\title{
PRODUÇÃO DE BIOMASSA ÁRBOREA E CARBONO ORGÂNICO EM POVOAMENTO DE Araucaria angustifolia (Bert.) O. Kuntze AOS 24 ANOS NO SUL DO ESTADO DO PARANÁ, BRASIL
}

\author{
Tree Biomass and Organic Carbon Production in an Araucaria \\ angustifolia (Bert.) O. Kuntze Stand 24 years old, in the South \\ of the Parana State, Brazil
}

Luciano Farinha Watzlawick ${ }^{1}$

\section{Resumo}

Atualmente é cada vez maior o interesse pela fixação de carbono em florestas plantadas, principalmente devido à sua elevada taxa de crescimento e conseqüente capacidade de remover o dióxido de carbono da atmosfera. Em função desse interesse e preocupação, o presente estudo teve por objetivos estimar a biomassa arbórea e o carbono orgânico nos diversos componentes das plantas (madeira do fuste, casca, galhos vivos, galhos mortos, ramos aciculados e raiz) de um povoamento de Araucaria angustifolia (Bert.) O. Kuntze aos 24 anos de idade. Concluiu-se que o estoque de biomassa é de $63 \mathrm{mg} \mathrm{ha}^{-1}$ e de carbono orgânico 26,82 mg $\mathrm{ha}^{-1}$, sendo que o componente que apresentou maior quantidade tanto de biomassa como de carbono foi a madeira do fuste, com $46,51 \%$ e $48,17 \%$, respectivamente.

Palavras-chave: Araucaria angustifólia; Fixação de carbono; Determinação de biomassa.

\section{Abstract}

Currently, it is greater the interest for the carbon fixture in manmade forests, mainly due to the high growing rate and consequently capacity to remove the carbon dioxide from the atmosphere. According to this interest and concerning, the present study had as objectives to estimate the tree biomass and organic carbon on the several components of the plant (stem wood, bark, alive branches, dead branches, acicular bunches and root), of an Araucaria angustifolia (Bert.) O. Kuntze stand, 24 years old. It was concluded that the biomass stored reached $63 \mathrm{mg} \mathrm{ha}^{-1}$ and the organic carbon $26.82 \mathrm{mg} \mathrm{ha}^{-1}$, being stem wood the component that presented the largest amount of biomass as well as the carbon, $46.51 \%$ and $48.17 \%$, respectively.

Keywords: Araucaria angustifolia; Carbon fixture; Biomass determination.

1 Eng. Florestal, Dr., Prof. Adjunto do Departamento de Agronomia, Centro de Ciências Agrárias e Ambientais, Universidade Estadual do Centro-Oeste (UNICENTRO), Rua Simeão Camargo Varela de Sá, 03, CEP 85040-080, Guarapuava (PR), farinha@unicentro.br 


\section{Introdução}

A Araucária (Araucaria angustifolia (Bert.) O. Kuntze., conforme Reitz (1979), é encontrada formando agrupamentos densos, principalmente na parte leste e central do planalto meridional do Brasil, abrangendo os Estados do Paraná, Santa Catarina e Rio Grande do Sul. Ocorre ainda, na forma de manchas esparsas, no sul do Estado de São Paulo e na região da Serra da Mantiqueira, estendendo-se até o sul de Minas Gerais e Rio de Janeiro. Essa espécie atravessa para a Província Argentina de Misiones e no Paraguai, distante $60 \mathrm{~km}$ do Rio Paraná, existe um núcleo de pinhal, completamente cercado pela mata latifoliada da Bacia do Rio Paraná.

A araucária é uma espécie florestal nativa brasileira que tem demonstrado o bom comportamento em plantações. Contudo, quando se confronta o seu rendimento com o de outras coníferas exóticas como as do gênero Pinus, na maioria dos casos, a araucária tem um desenvolvimento menor.

Atualmente é cada vez maior o interesse pela fixação de carbono em florestas plantadas, principalmente devido suas elevadas taxas de crescimento e conseqüente capacidade de remover dióxido de carbono da atmosfera. Porém, fatos políticos estão tornando este assunto especialmente interessante para os países que não fazem parte do chamado Anexo I do Protocolo de Quioto. Isto porque definições da Conferência das Partes realizada em Bonn em 2001 (COP 6) e reafirmadas na COP 7 em Marrakesh também em 2001 definiram que para estes países a emissão de Certificados de Redução de Emissões (CERs), que poderão ser negociados no mercado internacional, somente poderão ser gerados a partir de atividades induzidas pelo homem, ou seja, por florestamentos e reflorestamentos.

Para Schumacher et al. (2001), as florestas plantadas geralmente com fins econômicos e comerciais são orientadas por critérios técnicos, conforme um plano de manejo, definindo-se sua época de colheita. Porém, durante sua existência, essas florestas realizam a atividade de captura e fixação de carbono na madeira e nos demais componentes.

A remoção do dióxido de carbono da atmosfera ocorre por fotossíntese nos vegetais e sua liberação no processo de respiração, sendo parte desse carbono armazenado nos diversos compo- nentes das plantas, conforme Simpson e Botkin, citados por Schumacher et al. (2001).

Para Watzlawick (2003), as quantificações de biomassa e carbono mediante a utilização do método destrutivo em plantações florestais e nas florestas naturais, apesar de serem extremamente trabalhosas, apresentaram resultados satisfatórios, em plantações florestais, principalmente em função das diferenças existentes entre as idades, condições de manejo, desbastes, desramas e densidade de indivíduos por hectare, e nas florestas naturais, devido aos diferentes estágios de desenvolvimento e a composição de espécies.

Em função do exposto acima, o presente estudo teve por objetivos estimar a biomassa arbórea e o carbono orgânico nos diversos componentes da planta (madeira do fuste, casca, galhos vivos, galhos mortos, ramos aciculados e raiz) de um povoamento Araucaria angustifolia (Bert.) O. Kuntze., com 24 anos, visando analisar a fixação de carbono atmosférico.

\section{Materiais e métodos}

\section{Caracterização e localização da área de estudo}

A área de estudo está localizada entre as coordenadas $26^{\circ} 20^{\prime} 35^{\prime \prime}$ e $26^{\circ} 26^{\prime} 13^{\prime \prime}$, e $51^{\circ} 19^{\prime} 49^{\prime \prime}$ e 51'25'29'W, na Região Sul do Paraná, no município de General Carneiro - PR, Brasil, conforme apresentado na Figura 1.

O levantamento dos dados foi realizado em um povoamento de araucária com 24 anos de idade, de propriedade das Indústrias Pedro N. Pizzatto Ltda., empresa florestal de porte médio, que processa madeira e seus derivados.

Os solos da área são orgânicos e hidromórficos, pouco profundos e férteis, com predomínio de cambissolos associados com solos litólicos, bem como outras associações com podzólicos e latossólicos, além de solos orgânicos. O clima é caracterizado como subtropical úmido mesotérmico (Cfb), pela classificação de Köppen, com verões frescos, e a temperatura média anual variando entre $15^{\circ} \mathrm{C}$ a $19^{\circ} \mathrm{C}$, nos meses mais frios a mínima pode alcançar $-10^{\circ} \mathrm{C}$, enquanto nos períodos mais quentes as temperaturas podem alcançar até $36^{\circ} \mathrm{C}$.

A vegetação natural refere-se à Floresta Ombrófila Mista ou floresta com araucária, a qual 
cobria originalmente cerca de $200.000 \mathrm{~km}^{2}$ em todo o Brasil, ocorrendo no Paraná (40\% de sua superfície), Santa Catarina (31\%) e Rio Grande do Sul
(25\%) e em manchas esparsas no sul do estado de São Paulo (3\%), adentrando até o sul de Minas Gerais e Rio de Janeiro (1\%) (Carvalho, 1994).

FIGURA 1 - Localização da área de estudo.

Figure 1 - Study area localization.

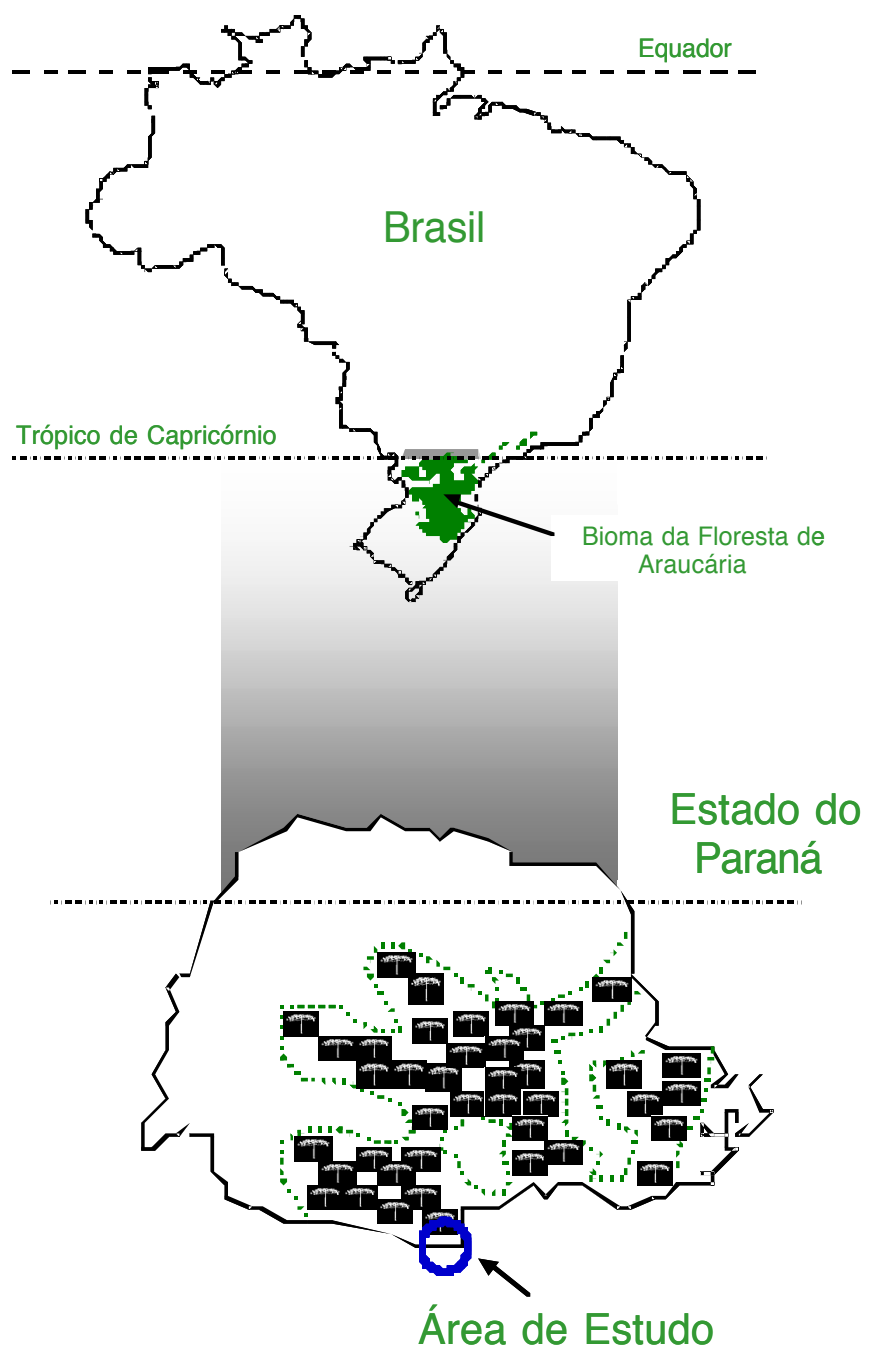

Conforme dados provenientes de inventário florestal fornecido pela empresa, o povoamento de Araucaria angustifolia em estudo possui uma densidade de 590 árvores por hectare, DAP médio de $13,94 \mathrm{~cm}$, altura total média de 10,18 m, área basal 17,76 m² e um volume médio de 100,31 $\mathrm{m}^{3} / \mathrm{ha}$.

\section{Procedimentos de campo e de laboratório}

Os dados de biomassa foram coletados no campo utilizando-se o método destrutivo de quantificação, utilizando-se uma amostragem de 7 (sete) árvores, distribuídas aleatoriamente no povoamento. Todos os indivíduos foram derrubados 
para obtenção das variáveis dendrométricas DAP, altura total e altura comercial.

Depois de abater cada árvore, seus componentes eram amostrados. Essas amostras eram pesadas no campo, em balança mecânica com precisão de 0,1 g para determinação do teor de umidade.

A amostragem dos ramos aciculados (grinpas) foi feita na ponta, meio e base da copa. No caso dos galhos, adotou-se o mesmo procedimento, retirando-se amostras com casca na extremidade, meio e base dos galhos. As amostras de casca do fuste foram retiradas na base, à meia altura e na ponta da árvore, nos mesmos locais onde foram retirados os discos para amostragem da madeira. A quantificação do peso total da casca foi feita por relações de fator de casca. Já a madeira do fuste era secionada e pesada diretamente em uma balança com capacidade para 300 kg. Após a amostragem os galhos foram removidos para coleta e pesagem dos ramos aciculados. Os galhos foram separados e pesados.

A biomassa radicial foi quantificada na área determinada como área teórica de ocupação de cada planta dentro do povoamento. Dado o espaçamento do plantio ser de $2,5 \mathrm{~m} \mathrm{x} \mathrm{2,0} \mathrm{m,} \mathrm{con-}$ siderou-se uma área útil de $5 \mathrm{~m}^{2}$, onde foi escavado até $0,5 \mathrm{~m}$ de profundidade e coletadas as raízes com diâmetro igual ou superior a $1 \mathrm{~cm}$.

Após a pesagem e amostragem dos diversos componentes, esses foram levados para laboratório e secos em estufa de renovação e circulação de ar a uma temperatura constante de $75^{\circ} \mathrm{C}$ até atingir o peso constante para posterior determinação de peso seco e preparação para análise química do teor de carbono orgânico.

As análises de carbono orgânico no tecido vegetal foram executadas de acordo com a metodologia proposta por Tedesco et al. (1995), realizadas no Laboratório de Ecologia Florestal, da Universidade Federal de Santa Maria, Estado do Rio Grande do Sul, Brasil.

\section{Resultados e discussões}

Considerando a biomassa total para a Araucaria angustifolia, conforme pode ser observado na Tabela 1 , verifica-se que a parte aérea possui $85,50 \%$ da biomassa total das árvores, estando subdividida na seguinte proporção: madeira do fuste $46,51 \%$, casca $21,95 \%$, ramo aciculado $5,63 \%$, galho vivo $4,62 \%$ e galho morto $1,79 \%$, restando 19,5 para a biomassa subterrânea (raízes).

Para Krapfenbauer e Andrae (1976), ao realizar estudo em povoamento de Araucaria angustifolia na região de Passo Fundo - RS, com 17 anos de idade, verificaram que a quantidade de biomassa do tronco representava $72,4 \%$ do total acima do solo. Observou-se ainda uma biomassa de $12,9 \%$ e $12,4 \%$ para casca e raízes, respectivamente.

Estudando um povoamento florestal de Pinus taeda com 10 anos de idade, Schumacher (2000) estimou a biomassa seca dos componentes acículas, galhos, casca e madeira em 13,6; 10,1; 7,7 e 60,1 $\mathrm{Mg} \mathrm{ha}^{-1}$, respectivamente. O carbono acumulado nesses componentes foi de 6,1; 3,7; 3,2 e 28,3 $\mathrm{mg} \mathrm{ha}^{-1}$ para as acículas, galhos, casca e madeira, respectivamente. Esses dados são provenientes de uma área com 950 árvores, em média, por hectare.

Como visto na Tabela 1, o povoamento de Araucaria angustifolia em estudo atingiu valores inferiores aos do Pinus, conforme apresentado anteriormente, aos 24 anos de idade e com uma densidade de 590 árvores por hectare, isto é, 63,00 mg ha $\mathrm{a}^{-1}$ de biomassa, o que corresponde a uma fixação de carbono de $26,82 \mathrm{mg} \mathrm{ha}^{-1}$, onde foram considerados os galhos secos e raízes, diferentemente do estudo realizado por Schumacher.

Schumacher, Hoppe e Barbieri (2002), em estudo realizado com povoamentos de Araucaria angustifolia em Quedas do Iguaçu - PR, com 14 e 27 anos de idade, encontraram 43,15 $\mathrm{mg} \mathrm{ha}^{-1} \mathrm{e}$ $173,83 \mathrm{mg} \mathrm{ha}^{-1}$ de produção de biomassa, 18,46 mg ha ${ }^{-1}$ e 79,04 mg ha ${ }^{-1}$ de carbono orgânico acumulado, respectivamente. Ressalta-se que os valores observados pelos autores não consideram as raízes, que serão discutidas separadamente. Os valores encontrados em povoamentos de 27 anos foram superiores aos do de 29 , no presente estudo, o que pode ser atribuído às condições edafoclimáticas e ao material genético.

As quantidades de biomassa e carbono nas raízes estimadas pelos mesmos autores acima referenciados em um povoamento de Araucaria angustifolia encontraram aos 27 anos de idade foram de $24,78 \mathrm{mg} \mathrm{ha}^{-1}$ e 10,81 $\mathrm{mg} \mathrm{ha}^{-1}$, respectivamente. Ressalta-se que a quantidade da biomassa de carbono contido nas raízes representa $12 \%$ da biomassa total para o povoamento, que se encon- 
tra em idade de corte raso. Krapfenbauer e Andrae (1976), trabalhando com a mesma espécie, porém com um povoamento com 17 anos de idade, encontraram um percentual de $12,4 \%$ em relação à biomassa total.

No que diz respeito aos quantitativos de carbono fixado, os percentuais encontrados neste estudo foram: madeira do fuste $(48,17 \%)$, casca $(20,69 \%)$, ramo aciculado (5,82\%), galho vivo
(4,51\%) e galho morto (1,79\%), restando 19,02\% para a biomassa subterrânea (raízes).

Os teores de carbono no povoamento de araucária, em termos percentuais, variaram de 39,98\%, para o componente galho morto, a 45,39\%, para o ramo aciculado. Para a madeira do fuste esse percentual foi de $44,51 \%$, valor inferior ao percentual dos ramos aciculados e superior aos percentuais contidos nos galhos mortos.

TABELA 1 - Valores de biomassa e carbono orgânico em povoamento de Araucaria angustifolia aos 24 anos de idade no Estado do Paraná, Brasil.

Table 1 - Biomass and organic carbon values in an Araucaria angustifolia stand, 24 years old, in Parana State, Brazil.

\begin{tabular}{|c|c|c|c|c|}
\hline Componente & $\begin{array}{l}\text { Biomassa } \\
\left(\mathrm{mg} \mathrm{ha}^{-1}\right)\end{array}$ & $\begin{array}{l}\text { Teor de } \\
\text { Carbono }\left(\mathrm{g} \mathrm{Kg}^{-1}\right)\end{array}$ & $\begin{array}{l}\text { Carbono } \\
\left.\text { Orgânico (mg ha }{ }^{-1}\right)\end{array}$ & $\begin{array}{l}\text { Carbono } \\
\text { Fixado }(\%)\end{array}$ \\
\hline Madeira do fuste & 29,30 & 445,10 & 12,92 & 48,17 \\
\hline Casca do fuste & 13,83 & 402,27 & 5,55 & 20,69 \\
\hline Ramo aciculado & 3,55 & 453,87 & 1,56 & 5,82 \\
\hline Galho vivo & 2,91 & 402,27 & 1,21 & 4,51 \\
\hline Galho morto & 1,13 & 399,83 & 0,48 & 1,79 \\
\hline Raiz & 12,29 & 414,94 & 5,10 & 19,02 \\
\hline Total & 63,00 & & 26,82 & 100,00 \\
\hline
\end{tabular}

Ao tratar os componentes separadamente, tanto com relação à produção de biomassa como o acúmulo de carbono orgânico, a distribuição percentual apresentou a seguinte ordem: madeira do fuste $>$ casca do fuste $>$ raiz $>$ ramos aciculados $>$ galhos vivos $>$ galhos mortos. Similaridades de resultados foram verificadas nos trabalhos de Schumacher, Hoppe e Barbieri (2002) com Araucaria angustifolia, aos 14 anos de idade: madeira do fuste $>$ casca $>$ acículas (grimpa) $>$ galhos vivos $>$ galhos mortos, e aos 27 anos de idade: madeira do fuste $>$ casca $>$ galhos vivos $>$ acículas (grimpa) > galhos mortos, ambos na região Quedas do Igua$\mathrm{çU}-\mathrm{PR}$.

De acordo com Satoo, citado por Valeri (1989), a produção de biomassa não está relacionada diretamente com a produção de matéria seca, mas sim com a idade do povoamento. Valeri (1989) complementa dizendo que a quantidade de biomassa varia em função das condições do povoamento, tais como: qualidade do sítio, altitude, fatores ambientais e silviculturais.

Os fatores que influenciam nas diferenças de produção de biomassa e acúmulo de car- bono orgânico em plantações florestais sob as mesmas condições edafoclimáticas relacionam-se principalmente ao potencial genético da espécie, fatores próprios inerentes à planta. Conforme Lugo, Brown e Chapman (1988), alguns estudos relacionam a produção com os fatores climáticos, mas poucos relacionam a produção com os fatores inerentes ao sítio.

Como se pode observar o maior percentual de produção de biomassa e acúmulo de carbono orgânico em povoamentos florestais encontra-se na madeira do fuste. Conforme Andrae (1978), o maior percentual encontra-se no tronco e esse tende a aumentar à medida que o povoamento envelhece. Pereira, et al. (1984) observaram que com o aumento da idade ocorre também um aumento substancial da proporção de madeira em relação à matéria seca total.

A produção de biomassa abaixo do solo varia com a espécie e o espaçamento (REIS et al. 1993; SCHUMACHER, 1995). Gonçalves et al. (2000) acrescentam que a contribuição do sistema radicular para a biomassa total da árvore varia em função da idade, onde os percentuais maiores ocor- 
rem na fase inicial do crescimento, sendo que a maioria dos fotoassimilados sintetizados pela planta é canalizada para a formação de copas e o sistema radicular. Essa contribuição somente mudará após o fechamento da copa, quando o acúmulo de nutrientes passa a ser mais intenso nos troncos, uma vez que a formação da copa atingiu uma fase de relativa estabilidade, pois o auto-sombreamento impõe uma área foliar máxima limite.

Os fatos acima mostram a variabilidade da magnitude destas variáveis, dado que são muito influenciadas pela espécie, pela densidade, pelo sítio e também pelas práticas de manejo. Portanto, é importante se ter muita cautela ao fazer qualquer extrapolação de resultados, sendo sempre importante se obter estimativas fidedignas no tocante à biomassa e ao conteúdo de carbono em plantios florestais.

Adicionalmente, é importante ressaltar que os quantitativos de biomassa da raiz variam muito com a espécie e o espaçamento, conforme observam Reis et al. (1993). Segundo os autores, a deficiência dessa informação dificulta a determinação precisa do balanço do carbono em um ecossistema florestal. Desta forma, é imprescindivel que mais estudos sejam feitos no sentido de elucidar a porção representada pela biomassa e pelo carbono fixado pelos diferentes tipos de floresta.

Rochadelli (2001), estudando a estrutura atômica de fixação de carbono em reflorestamentos de Mimosa scabrella (Bracatinga), em idades de 1 a 7 anos de idade, concluiu que a espécie apresenta uma concentração de carbono que varia entre 40 a $45 \%$ da biomassa total de madeira com casca, valores semelhantes aos apresentados na Tabela 1.

\section{Conclusões}

- Do total da biomassa em um povoamento de Araucaria angustifolia aos 24 anos de idade, $46,51 \%$ correspondeu à porção da madeira do fuste sem casca, 21,95\% à porção casca, 4,62\% a galhos vivos, $1,79 \%$ a galhos mortos, 5,63\% a ramos aciculados e 19,50\% à raiz.

- Do total de carbono fixado pela floresta, $48,17 \%$ representaram o componente madeira do fuste sem casca, 20,69\% à porção casca, 4,51\% a galhos vivos, 1,79\% a galhos mortos, 5,82 \% a ramos aciculados e 19,02 à raiz.
- Os teores de carbono nos componentes da araucária, em termos percentuais, variaram de $39,98 \%$ a $45,39 \%$, nos galhos mortos e ramos aciculados, respectivamente, demonstrando que é preciso ter cuidados ao utilizar valores desses teores de forma indiscriminada.

- A literatura brasileira apresenta muitas variações em termos de biomassa em diversos plantios sujeitos a diferentes condições de desenvolvimento, porém, os teores de carbono, dadas as variações observadas, foram bem mais estáveis, oscilando entre 40 a 50\%, com média em torno de $45 \%$ da biomassa seca.

\section{Referências}

ANDRAE, F. H. Ecologia florestal. Santa Maria: UFSM, 1978.

GONÇALVES, J. L. M.; MELLO, S. L. M. O sistema radicular das árvores. In: GONÇALVES, J. L. M.; BENEDETTI, V. Nutrição e fertilização florestal. Piracicaba: ESALQ/USP, 2000. p. 221-267.

KRAPFENBAUER, A.; ANDRAE, F. Inventur einer 17 jaehrigen Araukarienaufforstung in Passo Fundo, Rio Grande do Sul, Brasilien. Forstwesen, v. 93, n. 2, p. 70-87, 1976.

LUGO, A. E.; BROWN, S.; CHAPMAN, J. An analytical review of production rates and stem wood biomass of tropical forest plantations. Forest Ecology and Management, Amsterdam, v. 23, p. 179-200, 1988.

PEREIRA, A. R., et al. Concentração e distribuição de nutrientes em Eucalyptus grandis em função da idade, cultivado na região do cerrado. Brasil Florestal, Brasília, n. 59, p. 27-38, 1984.

REIS, M. das G. F., et al. Seqüestro e armazenamento de carbono em florestas nativas e plantadas dos estados de Minas gerais e Espírito Santo. In: EMISSÃO X SEQÜESTRO DE CO $\mathrm{CO}_{2}$ - UMA NOVA OPORTUNIDADE DE NEGÓCIOS PARA O BRASIL, RiO de Janeiro, 1994. Anais... Rio de Janeiro, 1994. p. 155-195.

REITZ, R.; KLEIN, R. M.; REIS, A. Madeiras do Brasil. Florianópolis. Lunardelli, 1979. p. 320 . 
ROCHADELLI, R. A estrutura de fixação dos átomos de carbono em reflorestamentos (Estudo de caso: Mimosa scabrella Bentham, bracatinga). 2001. 86 f. Tese (Doutorado em Ciências Florestais) - Universidade Federal do Paraná, Curitiba, 2001.

SANQUETTA, C. R. Inventário contínuo em floresta natural: implantação de um sistema de monitoramento de crescimento e produção. Indústrias Pedro N. Pizzatto/FUPEF, 1998. (Relatório de Pesquisa).

SCHUMACHER, M. V. Naehrstoffkreislauf in verschiedenen Bestaeden von Eucalyptussaligna (Smith), Eucalyptus dunnii (Maiden) und Eucalyptus globulus (Labillardière) in Rio Grande do Sul, Brasilien. 1995. 167 f. Tese (Doutorado em Ecologia e Nutrição Florestal) - Universitäet für Bodenkultur, Wien, Áustria,1995.

SCHUMACHER, M. V. Quantificação do carbono orgânico em florestas de Pinus taeda L, com diferentes idades. Santa Maria: UFSM, 2000. (Relatório de pesquisa).

SCHUMACHER, M. V., et al. Quantificação do carbono orgânico em floresta de Acacia mearnsii De Wild em diferentes idades. In: SIMPÓSIO LATINO-AMERICANO SOBRE MANEJO FLORESTAL, 2. Santa Maria. 2001. Anais... Santa Maria:[S. n.], 2001. p. 387-399.
SCHUMACHER, M. V.; HOPPE, J. M.; BARBIERI, S. Quantificação da biomassa e do conteúdo de nutrientes no corte raso de uma floresta de Araucaria angustifolia (Bert.) $O$. Ktze. na região de Quedas de Iguaçu-PR. Santa Maria: UFSM, 2002. (Relatório de pesquisa).

TEDESCO, M. J.; VOLKWEISS, S. J.; BOHNEN, H. Análise de solos, plantas e outros materiais. Porto Alegre: UFRGS, Departamento de Solos/ Faculdade de Agronomia, p. 174, 1995. (Boletim Técnico, 5).

VALERI, S. V. Exportação de biomassa e nutrientes de povoamentos de Pinus taed $a \mathbf{L}$, desbastados em diferentes idades. Curitiba, 1988. $164 \mathrm{f}$. Tese (Doutorado em Ciências Florestais) - Setor de Ciências Agrárias, Universidade Federal do Paraná, 1988.

WATZLAWICK, L. F. Estimativa de biomassa e carbono em floresta ombrófila mista e plantações florestais a partir de dados de imagens do satélite IKONOS II. 2003. 120 f. Tese (Doutorado em Ciências Florestais) - Setor de Ciências Agrárias, Universidade Federal do Paraná. Curitiba, 2003.

Recebido: 27/06/2005 Aprovado: 30/09/2005 